\title{
СТАНОВЛЕНИЕ ПРЕДСТАВЛЕНИЙ О ПОЗНАВАТЕЛЬНЫХ ПОТРЕБНОСТЯХ В ПРОЦЕССЕ РАЗВИТИЯ ПСИХОЛОГИЧЕСКОЙ ТЕОРИИ
}

\author{
Н.Р. Апреликова \\ Московский инновационный университет
}

\begin{abstract}
Аннотация: В статье рассмотрены периоды развития представлений о познавательных потребностях личности в рамках становления психологической теории. Осуществлен анализ становления представлений о сущности, структуре, функциях, направленности и механизмах развития познавательных потребностей, которые рассматриваются как в психологии личности, так и сочиальной психологии. С различных точек зрения рассматриваются особенности изучения познавательной деятельности в гуманитарных науках и в прочессе становления психологических (теоретических и эмпирических) подходов к ее исследованию. Проведен анализ факторов, оказывающих воздействие на развитие познавательной активности человека, которая трактуется как «ненасыщаемая» потребность в обладании знаниями.
\end{abstract}

Ключевые слова: история психологии, познавательные потребности, интеллектуальное развитие, эмоциональные переживания, активность личности, ненасыщаемые потребности, теоретическое мышление, познавательная устойчивость

\section{ESTABLISHMENT OF COGNITIVE NEEDSIN THE DEVELOPMENT OF PSYCHOLOGICAL THEORY}

\author{
N.R. Aprelikova \\ Moscow Innovation University
}

\begin{abstract}
The article examines the periods of development of ideas about the cognitive needs of the individual within the framework of the formation of psychological theory. The analysis of the formation of ideas about the essence, structure, functions, direction and mechanisms of development of cognitive needs, which are considered both within the framework of personality psychology and social psychology, is carried out. The work, from various points of view, examines the features of the study of cognitive activity in the humanities and in the process of the formation of psychological (theoretical and empirical) research approaches. The analysis of factors influencing the development of human cognitive activity, which is considered as an "unsaturated» need for knowledge, is carried out.

Keywords: history of the formation of psychology, cognitive needs, intellectual development, emotional experiences, personality activity, unsaturated needs, theoretical thinking, cognitive stability

Одной из классических проблем психологии является изучение познавательных потребностей личности (Апреликова, Китова, 2018; Гараганов, Китова, 2016; Китова, 2019; Нестик и др., 2017). Нужно отметить, что этой изучение проблемы имеет глубокие исторические корни. Еще в период античности (VII в. до н.э.-IV в. н.э.) ею занимались Гераклит, Сократ, Аристотель, Эпикур, Плотин, К. Галлен. Они обосновали позиции, ставшие в дальнейшем частью современной психологической науки. Например: соотношение телесного и психического, чувственного и рационального в познании, врожденного и приобретенного, мыш-
\end{abstract}


ления и речи, взаимовлияния личности и общества. Представители Милетской школы в тот же период заложили основы многих психологических понятий, таких как: мотив, личность, образ. Еще Платон заявлял о динамической структуре личности. Древними философами обговаривались функциональные особенности и механизмы мышления и памяти (Платон), воображения и представлений (Аристотель), рефлексии (Плотин).

Позже, в период с IV и до XVII вв., научное познание вытеснялось и подавлялось религиозными доктринами. Тем не менее, тогда же и происходило разделение понятий вера и знание. В частности, Авиценна, в рамках теории двух истин, постулировал самостоятельное значение «истинного знания», реализуя данную концепцию в собственных исследованиях и методах познания человека единого телом и душой.

В XV в. X. Вивес, основываясь на эмпирическом подходе к анализу чувственныХ восприятий, утверждал, что индукция - это строительный материал для последующей работы интеллекта, а Х. Уарте в книге «Исследования способностей к наукам» (1575) выделил в качестве основных способностей (природных дарований) человека память, воображение и интеллект, обосновал влияние каждого из этих «дарований» на предрасположенность к той или иной деятельности.

В Новое время (начиная с XVII в.) происходит становление рационалистической теории познания. Развиваются учения о мыслительных процессах и сознании как предмете, а понятие «душа» становится излишним. Так, согласно Р. Декарту, сущность души - в сознании. Она выступает как «мыслящее начало», реализуемое в мыслительной деятельности и непосредственно взаимодействующее с телом. Декарт указывал на то, что человек способен осознавать психические процессы, а физиологические - нет. Через призму данной позиции, велись рассуждения об осознанности. Отмечалось, что процесс познания имеет осознаваемую природу, т.е. непосредственная работа человеческого разума доступна восприятию путем самонаблюдения, а также - анализа внутренних и внешних переживаний (Т. Гоббс, Р. Декарт, Б. Спиноза, Г. Лейбниц).

Следующий, XVIII в., был пропитан идеями материалистической природы психики человека. Отмечалось, что эволюционно-материалистические представления основываются на чувственном опыте человека, а биологические задатки играют ведущую роль в формировании человека. Этих позиций придерживались такие ученые, как Э. Кондильяк, Ж.Ж. Руссо, И. Герцбарт, М.В. Ломоносов. Так, М.В. Ломоносов считал, что умственное развитие детерминировано больше биологическими, нежели социальными факторами, и зависит не только от старания, но и от природных задатков. В свою очередь, врач и философ Ж. Ламерти определял познание как процесс, начинающийся посредством чувственного восприятия реальности, который дополняется опытом экспериментального исследования 
и завершается рациональным обобщением фактов, подвергающихся опытной проверке (Ламерти, 1976).

На рубеже XIX-XX столетий происходит становление психологии как нового научного направления. Открытие В. Вундтом в 1879 г. первой в мире психологической лаборатории в дальнейшем создало научную платформу для использования экспериментальных методов изучения психических процессов. Первым экспериментально-психологическим исследованием когнитивных психических процессов стало исследование памяти и обучаемости, проведенное Г. Эбингаузом. В то время сформировалось много психологических школ и направлений. Использование эксперимента для изучения психологических явлений выходит из стен лабораторий и начинает получать всеобщее признание и интегрироваться в разные сферы жизнедеятельности мирового психологического сообщества.

Психология уверенно занимает собственную позицию в сфере экспериментальных исследований. В XIX в. И.М. Сеченов разработал программу развития психологии, как экспериментальной дисциплины, ему первому удалось сформулировать и обосновать идею объективного изучения внутреннего мира человека, в том числе и процессов познания. Позже, уже в веке XX-м, С.Л. Рубинштейн отмечал, что введение эксперимента не только вооружило психологию «новым для нее мощным методом научного мышления, но и по-новому поставило вопрос о методике психологического исследования в целом, выдвинув новые требования и критерии научности всех видов опытного исследования в психологии» (Рубинштейн, 1989, с. 71-72). Так XX в. ознаменовался не только признанием системного подхода в изучении психики, но и масштабным интересом к анализу познавательных потребностей человека.

С древних времен и до наших дней, несмотря на длительный период обсуждения проблемы, единого мнения в определении феномена познавательных потребностей так и не сформировалось. До сих пор в различных научных источниках можно встретить разнящиеся, хотя и близкие по смыслу, трактовки познавательных потребностей, которые определяются как: «умственная активность», «потребность в познании», «исследовательская потребность», «потребность в умственной деятельности» и т.д.

К примеру, в современном психологическом словаре под редакцией С.Ю. Головина познавательная потребность определяется, как потребность во внешних впечатлениях, отмечается, что «...потребность в приобретении новых знаний складывается лишь в ситуациях, способствующих осознанию необходимости этих знаний для жизни и деятельности» (Словарь практического..., 1998). Л.И. Божович обозначает познавательную потребность, как потребность в новой информации, где сама информация рассматривается в различных формах - как «новое знание», «новое представление о мире» или «новый стимул» (Божович, 1972). Г.И. Щукина определяет «познавательную потребность, как чувство «ин- 
теллектуального голода» (Щукина, 1962: 10), а В.С. Юркевич рассматривает ее, как «потребность в деятельности, направленной на получение нового знания» (Юркевич, 1980).

Не сложилось методологического единства и в зарубежной научной литературе. К примеру, А.Р. Коэн потребность в познании трактует, как «потребность структурировать соответствующие ситуации смысловыми, интегрированными способами» (Cohen, 1957: 80), а Д. Кочиоппо и Р. Петти определяют ее, как «устойчивое индивидуальное выражение стремления людей участвовать в процессе усиленной мыслительной деятельности и получать от этого удовольствие» (Cacioppo, Petty, 1982: 117). Разнообразие в оценке и интерпретации познавательных процессов сохраняется и на современном этапе развития психологии. В частности, М.А. Холодная отмечает, что познавательная потребность - это потребность в приобретении новой информации, которую можно рассматривать как потребность в исследовании окружающей среды, коренящейся в природе живого (Холодная, 2002).

Вместе с признанием психологами ведущей роли интеллектуальных способностей человека в начале 50-х гг. прошлого века познавательная потребность обретает статус самостоятельной психологической категории и выделяется в отдельную область изучения. К проблеме изучения роли потребностей в познавательной деятельности обращались как многие отечественные (Б.Г. Ананьев, Л.И. Божович, Н.Ф. Добрынин, В.С. Ильин, В.С. Юркевич, М.А. Холодная и др.), так и зарубежные ученые (А. Маслоу, 3. Фрейд, Э. Фромм, К. Обуховский и др.).

Научные представления о влиянии общих потребностей на развитие познавательной деятельности различны, как в понимании самого феномена, так и его структурных и содержательных элементов, специфики развития в онтогенезе (Балова, Китова, 2011; Узденов, Китова, 2009). Тем не менее, можно проследить определенную хронологию развития этого направления в рамках различных психологических теорий (Хубиева, Китова, 2009; Субъект труда..., 2019). А. Маслоу, изучая мотивы поведения личности, указал на динамические (протяженные во времени) характеристики человеческих потребностей, отметив, что потребности, детерминирующие активность личности, редко достигают своего полного удовлетворения, поскольку «человек всегда хочет быть первоклассным или настолько хорошим, насколько он может быть» (Маслоу, 1982: 113). При этом, как только одна потребность удовлетворяется, сразу же появляется другая, которая перенаправляет внимание и усилия человека на следующее достижение. Автор отметил, что потребности организованы в иерархическую структуру, с явным эффектом доминирования одних потребностей относительно других, а высшим мотивом деятельности является духовный уровень. Он указал на наличие потребностей в наиболее полном использовании человеком своих способностей, талантов, возможностей для достижения различных целей, а также выделил и описал 
потребность в самоактуализации. Многие из высших потребностей личности, связанные с реализацией познавательных потребностей человека, по утверждению А. Маслоу, близки к потребностям в самоактуализации и, практически, не насыщаемы (Маслоу, 1982). Таким образом, автор выделил механизмы функционирования познавательных потребностей, их (потребностей) процессуальную цикличность и ненасыщаемость.

Непосредственно проблемы познавательных потребностей рассматривали многие советские ученые, которые подчеркивали их значимость в выработке новых знаний, отмечая, что эти потребности, наряду с потребностями в поиске знаний, относятся к группе интеллектуальных потребностей (Тихомиров, 1974). Исследователями отмечалось, что поиск новой информации, потребность в новых впечатлениях, направленность деятельности на получение нового знания - все эти феномены лежат в основе познавательной активности личности (Божович, 1972). Здесь необходимо привести взгляды А.Ф. Лазурского, считавшего познавательную активность исходным понятием психологии, рассматривавшего в качестве критерия классификации личностей - уровень проявления активности. По мнению ученого, стремление человека к преобразованию внешней среды согласно его влечениям и потребностям, выраженное через творчество, является ярким показателем познавательных потребностей личности (Лазурский, 1921). Советские исследователи так же указали, что познавательная активность, характеризуется «ненасыщаемостью», связана с постановкой новых целей и непрерывным циклом дальнейшей активизации (формирования) познавательного интереса.

Следующая позиция связана с тем, что познавательная потребность сопряжена с эмоциональными переживаниями, - например, с такой положительной эмоцией, как «радость познания». Это позволяет говорить о единстве интеллектуального и эмоционального компонентов познавательных потребностей. Эмоции, выступающие в качестве конкретной психической формы познавательной потребности, выражают активную сторону этой потребности и являются побудителями к дальнейшему познавательному действию (Рубинштейн, 2019). Таким образом, познавательная потребность связана не только с фактом приобретения новых знаний или расширением кругозора, но и с эмоциональными импульсами в процессе их реализации. К положительным эмоциям такого рода можно отнести чувство удовлетворения, возникающее в процессе познавательной деятельности, приподнятого настроения, иногда даже - интеллектуального восторга. Отмечается, что наличие позитивного эмоционального фона способствует развитию интеллектуальных способностей без «тяжелых усилий» - незаметно, быстро и легко. При отсутствии позитивных эмоций (или же при наличии отрицательных) интеллектуальные способности «не удается развить и за долгие часы напряженной умственной работы» (Психология одаренности..., 1996: 66). Такого рода связи между эмоциональными и интеллектуальными компонентами позна- 
Научные труды Московского гуманитарного университета

2020 № 5

вательных потребностей не всегда очевидны, как и связывающие их механизмы. Так, С.Л. Рубинштейн писал, что «эмоциональность, или аффективность, - это всегда лишь одна, специфическая, сторона процессов, которые в действительности являются вместе с тем познавательными процессами, отражающими - пусть специфическим образом - действительность. Эмоциональные процессы, таким образом, никак не могут противопоставляться процессам познавательным, как внешние, друг друга исключающие противоположности». И далее: «в эмоциональных процессах устанавливается связь, взаимоотношение между ходом событий, совершающимся в соответствии или в разрез с потребностями индивида, ходом его деятельности, направленной на удовлетворение этих потребностей, с одной стороны, и течением внутренних органических процессов, захватывающих основные витальные функции, от которых зависит жизнь организма в целом, - с другой» (Рубинштейн, 2019: 552).

В эмпирических исследованиях Ю.Е. Виноградова, направленных на анализ влияния эмоциональных процессов на структуру мыслительной деятельности, было отмечено, что «без эмоциональной активации невозможно объективно верное решение субъективно сложных мыслительных задач, хотя наличие этой активации еще не гарантирует достижение объективно верного результата» (Виноградов, 1972: 72). Автор также отмечал, что эмоции регулируют и течение самого познавательного поиска, выполняя в мышлении эвристическую функцию.

Таким образом, исследования, проводимые в 70-гг. XX в., позволили закрепиться в научной литературе положению о сопряженности познавательных потребностей с одновременным наличием активного эмоционального фона, вызываемого либо самим процессом умственного труда, либо предметом познания, либо перспективой (ожиданием) получения результата.

Эмоции, в частности, удовольствие от интеллектуальной деятельности, лежат в основе механизмов ненасыщаемости познавательной потребности. Этой позиции придерживались многие авторы. Так, Д. Качиоппо и Р. Петти отмечали, что в основе познавательной потребности лежит мотив получения удовольствия от умственной работы, жажда проникновения в суть изучаемого явления. Однако потребность в глубине познания у разных людей имеет различную степень выраженности. Авторы, согласно своей концепции «межличностных различий в познавательной потребности», утверждали, что низкая потребность в познании свидетельствует об отсутствии удовольствия от мыслительной деятельности и наоборот, высокая познавательная потребность побуждает человека к деятельности, благодаря которой человек стремится к познанию на протяжении всей своей жизни.

Следующая позиция связана с тем, что структура познавательной потребности подвержена изменениям в ходе индивидуального развития человека. По словам А.В. Брушлинского, такого рода изменения детерминированы закономер- 
Научные труды Московского гуманитарного университета

2020 № 5

ностями онтогенеза и социальной историей личности, и потому могут считаться важными симптомами индивидуального развития человека (Брушлинский, 1997: 31). В отечественной психологии сложилось мнение, что индивидуально-личностный характер познания проявляется, прежде всего, в мотивационной направленности познавательного процесса, при выделении субъектом значимых и второстепенных для него сторон изучаемого объекта.

В.Г. Асеев рассматривает проблему соотношения объективного и субъективного в познании, которое своеобразно проявляется при анализе объективности познавательной деятельности. С одной стороны, познание должно быть беспристрастным, что является одним из важнейших условий его объективности. С другой стороны, всякое познание имеет определенное побуждение, практическое или общепознавательное, и исходит из сложившихся теоретических положений или конкретных гипотез, т.е. детерминируется определенной системой ожиданий, установок, диспозиций и др. Таким образом, «человек всегда так или иначе заинтересован в определенном исходе познания, следовательно, оно (познание) всегда в той или иной мере пристрастно, подчинено побуждению или целой системе побуждений, которые могут искажать его истинность или ограничивать масштабы познавательной деятельности» (Асеев, 1993: 49).

Необходимо отметить и гипотезу Г.Дж. Фейста, согласно которой уровень интереса к науке может быть предсказан выраженностью познавательной потребности. Автор отмечает, что в своих действиях человек ориентируется на собственную конституциональность (индивидуально-личностные особенности), так же, как и на внешние условия среды, - условия, в рамках которых он имеет возможность к осуществлению тех или иных действий безотносительности к свойствам своего характера. Познавательные потребности активно влияют на особенности научного интереса, что создает возможности для неограниченных перспектив развития познавательного интереса личности (Feist, 2012).

В психологических теориях обосновывается и целый ряд особенностей анализа различных аспектов познавательной потребности, таких как становление познавательных потребностей, их связь с другими потребностями, динамика развития, цикличность и т.д. Так, 3. Фрейд указывал на детские впечатления как первооснову взрослых влечений к познанию, выполняющих компенсаторную функцию сексуальным влечениям, а Э. Фромм отмечал, что наличие стремления к познанию, к освоению мира является одним из глубоких интимных влечений личности - желанием познать логику окружающего мира, удовлетворить свое стремление к пониманию смысла существования. К. Обуховский считал, что процесс познания выступает активной индивидуальной деятельностью, которая «динамизирована посредством факторов, связанных с самим появлением проблемы, требующей познания, и может считаться, следовательно, в определенном смысле апрактичной» (Обуховский, 1971: 63). 
$\mathrm{C}$ середины XX в. психологами признается, что развитие познавательной потребности положительно сказывается на формировании мотивации и личности в целом. Указывается, что познавательная потребность способствует интенсивному развитию интеллектуальных процессов (восприятия, мышления, воображения) и отмечается, что возможно формирование такого типа жизненной мотивации личности, при котором познавательная потребность становится ведущим мотивом жизнедеятельности (С.Л. Рубинштейн, А.Н. Леонтьев, В.Г. Асеев, В.А. Петровский, В.А. Иванников, О.К. Тихомиров). Специалисты стали говорить и о взаимной обусловленности мотивов и типов поведения в сфере познавательной активности личности.

Е.Е. Васюкова разделила познавательные потребности на ситуативные и устойчивые, основываясь на том, что уровни развития познавательной потребности могут различаться по уровню устойчивости, могут оказывать соответствующее воздействие на структуру и продуктивность когнитивной деятельности. Предполагается, что повышенный уровень приводит к возрастанию креативности мышления, усиливает разнообразие и оригинальность идей. Автор отмечает, что чем выше степень неопределенности проблемных жизненных ситуаций, тем больше значение устойчивости познавательной потребности и уровня ее сформированности (Васюкова, 1986).

Подробно рассматривая специфические особенности познавательных потребностей, авторы не оставили без внимания и ее структурные характеристики. Так, В.С. Юркевич выделила две формы познавательной потребности:

- первая связана с усвоением готовых знаний (знание усваивается, а не создается), обуславливается интеграцией и систематизацией этих знаний, а также формируется потребность в накоплении (потреблении) готовых знаний;

- вторая отражает характер получения нового знания в ходе исследования реальной жизни, увязывается с определенной целью, эмоциональной удовлетворенностью, интересом к проблемным ситуациям, а также стремлением к творческой деятельности. Автор указал, что «само по себе осуществление познавательной деятельности усиливает познавательную потребность» (Юркевич, 1980).

Основываясь на представленных выше положениях, было выделено три уровня потребности в познавательной деятельности:

- потребность в впечатлениях, биологической предпосылкой которой выступает ориентировочный рефлекс, выдвинуто предположение о том, что потребность во впечатлениях является основой познавательной потребности (Нюттен, 2002);

- период любознательности характеризуется стихийно-эмоциональным характером, который связан с интересом к конкретному объекту, как целостному явлению. Такой интерес могут вызывать, например, различные занятия (спортом, музыкой, танцами и т.д.). На этом уровне познавательная деятельность но- 
сит стихийный характер, зачастую продиктована эмоциональными паттернами, а познавательная активность еще не обусловлена социально значимыми обстоятельствами;

- на третьем, высшем уровне, познавательные потребности характеризуются осознанным выбором социальной ситуации развития и целенаправленностью познавательной деятельности. Развиваются более устойчивые познавательные потребности, приводящие к объективно более значимым результатам (Юркевич, 1980).

Данное направление исследований получило продолжение. Так, В.С. Ильин выделил уже четыре уровня развития познавательных потребностей (реакция на стимулы - объединение впечатлений - формирование знания - потребность в поиске причинно-следственных связей): постоянно усложняясь, потребность в познании создает благоприятные условия для развития способов мышления. Автор отмечает, что познавательная потребность причастна к любым видам умственной деятельности, лежит в основе умственной одаренности и утверждает, что познавательная потребность не связана с практическими ожиданиями и целями, т.е. она бескорыстна. Такой подход позволяет отграничить истинные познавательные потребности от искусственных потребностей в познании (реализуемых посредством волевых усилий), детерминированных необходимостью удовлетворения иных потребностей (в наградах, достижениях и т.д.) (Ильин, 1971).

Позже исследователи стали характеризовать познавательные потребности как самоорганизующиеся, не требующие внешнего стимулирования, т.к. в процессе познания человек выступает не только созидателем (производителем) нового знания, но и его потребителем.

В научной литературе появились рассуждения о многих дополнительных характеристиках познавательных потребностей, таких как: различия по широте и глубине познания; экстенсивности/интенсивности познавательной деятельности, содержательных и структурных характеристиках познавательных потребностей, проблемам формирования, возрастным особенностям и т.д. (Мясищев В.Н., Божович Л.И., Шаров Ю.В., Л Леонтьев В.Г., Брандт, Р.А., Юркевич В.С., и др.).

Одним из первых проблему познавательной потребности как проявления «психической энергии» поставил А.Ф. Лазурский (Лазурский, 1921). Она отождествляется им с основным понятием его системы - понятием нервно-психической энергии. С точки зрения Лазурского, необходимо отличать понятия воли и энергии (активности). Энергия выступает как внутренний источник, определяющий уровень психической деятельности. Лазурский подчеркивал, что энергия и активность - не волевое усилие, а нечто гораздо более широкое, лежащее в основе всех вообще наших душевных процессов и проявлений. Количество нервно-психической энергии, степень активности стали основанием для классификации адаптационных характеристик личности, которые представлены ниже: 
- низший психический уровень: индивид недостаточно приспособлен к внешней среде, которая подчиняет себе слабую психику, в результате личность не дает и того немногого, что могла бы дать обществу;

- средний тип: индивид хорошо приспосабливается, приноравливается к внешней среде и находит в ней место, соответствующее внутреннему психическому складу («эндопсихике»);

- высший тип: индивид отличается стремлением переделать внешнюю среду согласно своим влечениям и потребностям. На этом уровне ярко выражен процесс творчества (к высшему уровню автор относит талантливых людей и гениев), третий высший уровень автор связывает с наличием ярко выраженных познавательных потребностей и интересов (Волкова и др., 2005: 21).

В заключение можно указать еще на ряд положений, развиваемых в рамках теории познавательных потребностей:

- познавательные потребности выступают самостоятельным видом потребностей и автономны, т.е. независимы от витальных потребностей;

- непрерывная изменчивость внешней среды и целей личности непрерывно активирует познавательные потребности, как следствие «жажда» знаний носит ненасыщаемый характер;

- к внутренним источникам активизации познавательных потребностей относится информация, получаемая в ходе онтогенетического взросления;

- потенциал и уровни познавательных потребностей напрямую зависят от природных свойств человека (возрастных, нейродинамических), обусловленных индивидуальным опытом и ступенями развития интеллектуальных способностей;

- познавательные потребности оказывают воздействие на все виды умственной деятельности и даже могут быть отнесены к исходным и самым общим предпосылкам умственной одаренности, возможно, составляют их единую основу.

Спорные позиции связаны с утверждением об исключительно врожденном (биологическом) характере познавательных потребностей. В этом отношении можно выделить позиции И.П. Павлова и А. Левицкого, которые отмечали, что познавательные потребности, подобно биологическим потребностям, имеют врожденную нейрофизиологическую основу. Однако, полагал Левицкий, «физиологические, а так же и биологические основы познавательной тенденции осуществляются не только происходящим в мозге человека механизмом, но и благодаря формированию определенного стереотипа психофизиологической деятельности на основе предшествующего опыта, образующегося в ходе личной жизни индивида» (Lewicki, 1959: 183).

Также важно отметить, что развитие потребности в знаниях тесно связано с общим развитием личности, с ее умением и навыками находить в содержании изучаемых наук и во внешней среде ответы на жизненно важные вопросы. 


\section{СПИСОК ЛИТЕРАТУРЫ}

Апреликова Н.Р., Китова Д.А. (2018) Структура потребностей студенческой молодежи в знаниях по психологии // Институт психологии Российской академии наук. Социальная и экономическая психология. Т. 4. № 2 (14). С. 110-133.

Асеев В.Г. (1993) Личность и значимость побуждений. М.: Институт психологии РАН.

Божович Л.И. (1972) Проблемы развития мотивационной сферы ребенка. Изучение мотивации поведения детей и подростков. М.: Педагогика.

Васюкова Е.Е. (1986) Уровни развития познавательной потребности и их проявление в мыслительной деятельности: автореферат дис. ... кандидата психологических наук. М.

Виноградов Ю.Е. (1972) Эмоциональная активация в структуре мыслительной деятельности человека. Дис. ... канд. психол. наук. М.

Волкова А.И., Дмитриева И.А., Кукушкин В.С., Пижугийда В.В. (2005) Психология и педагогика. М.: ИКЦ «МарТ»; Ростов-на-Дону.

Гараганов А.В., Китова Д.А. (2016) Методологические принципы исследования потребностей как основы социальной активности личности // Вестник Университета Российской академии образования. № 2. С. 104-107.

Журавлев А.Л., Китова Д.А. (2020) Социально-психологические ресурсы развития общества в условиях цифровых технологий // Социологическая наука и социальная практика. Т. 8. № 2. С. 24-40.

И вновь на перепутье? Постсоветским трансформациям 30 лет... (2019) М.: Новые печатные технологии.

Ильин В.С. (1971) Проблемы воспитания потребности в знании у школьников. Ростов-на-Дону.

Китова Д.А. (2019) Отечественная психология в условиях развития глобальных процессов // Психологический журнал. Т. 40. № 2. С. 128-131.

Китова Д.А., Балова Д.Ю. (2011) Психологические особенности представлений студентов о создании семьи [Электронный ресурс] // Прикладная психология и психоанализ: электрон. науч. журн. № 1. URL: http://ppip.idnk.ru (дата обращения: 12.12.2020).

Китова Д.А., Китов (2018) М.А. Психологические критерии в структуре моделей государственного управления / Психологические исследования глобальных процессов: предпосылки, тенденции, перспективы. М.: Институт психологии РАН. C. $333-350$.

Лазурский А.Ф. (1924) Классификация личностей. Л.: ГИЗ.

Ламерти Ж.О. (1976) Человек-машина. М.: Мысль.

Маслоу А. (1982) Самоактуализация // Психология личности. Тексты. М.: МГУ.

Нестик Т.А., Журавлев А.Л., Соснин В.А., Китова Д.А., Юревич А.В. (2017) 
Массовое сознание и поведение: тенденции социально-психологических исследований. М.: Институт психологии РАН.

Нюттен Ж. (2002) Мотивация, действие и перспектива будущего. М.: Смысл.

Обуховский К. (1971) Психология влечений человека. М.; Прогресс.

Проблема субъекта в психологической науке. (2000) Отв. ред.: А.В. Брушлинский. М.: Академический проект.

Психологическая наука в России XX столетия: проблемы теории и история. (1997) М.: Институт психологии РАН.

Психология одаренности детей и подростков. (1996) М.: Академия.

Рубинштейн С.Л. (2019) Основы общей психологии. СПб.: Питер.

Словарь практического психолога. (1998) М.: АСТ, Харвест.

Субъект труда и организационная среда: проблемы взаимодействия в условиях глобализации. (2019) Тверь: ТвГУ.

Тихомиров О.К. (1974) Познавательная потребность // Проблемы формирования социогенных потребностей. Тбилиси, С. 102-105.

Узденов Т.М., Китова Д.А. (2009) Представления студентов о целях и средствах достижения экономического благополучия // Гуманизация образования. № 3 . C. 129-133.

Ушаков Д.В., Журавлев А.Л., Юревич А.В. (2013) Перспективы психологии в решении задач российского общества. Часть III. На пути к технологиям согласования социальных институтов и менталитета // Психологический журнал. Т. 34. № 6. C. 5-25.

Холодная М.А. (2002) Психология интеллекта: Парадоксы исследования. 2-е изд., перераб. и доп. СПб.: Питер.

Хубиева Р.Т., Китова Д.А. (2009) Психологическая готовность молодежи к экономическим отношениям в современных условиях // Гуманизация образования. № 1. С. 104-109.

Щукина Г.И. (1962) Формирование познавательных интересов учащихся в процессе обучения. М.: Педагогика.

Юркевич В.С. (1980) Развитие начальных уровней познавательной потребности // Вопросы психологии. № 2. С. 83-92.

Cacioppo J.T., Petty R.E. (1982) The need for cognition // Journal of Personality and Social Psychology. Vol. 42. Issue 1. P. 116-131.

Cohen A.R. (1957) Need for cognition and order of communication as determinants of opinion change // The order of presentation in persuasion / C.I. Hovland (Ed.)/ New Haven: Yale University Press, P.79-87.

Feist G.J. (2012) Predicting interest in and attitudes toward science from personality and need for cognition // Personality and Individual Differences. Vol. 52, Iss. 7 P. 771-775.

Lewicki A. (1959) Rola abstrakcji poznytywnej i negatywnej w procesie uczenia sie nowych poj. Studia Psychologiczne. T. 3. 7 P. 71-75.

Nuttin J. (1980) Theorie de la motivation humaine. Presse univ. de France. 
Апреликова Наталия Руслановна - младший научный сотрудник Высшей школы бизнес-технологии, Московский инновационный университет, 119017, г. Москва, ул. Малая Ордынка, д. 7. Тел.: +7 (495) 963-09-46. Эл. адрес: aprelikovanr@mail.ru

Aprelikova Natalia Ruslanovna - Junior researcher at the Higher school of business technology, Moscow Innovation University, 119017, Moscow, Russia, st. Malaya Ordynka, 7. Tel.: +7 (495) 963-09-46. E-mail: aprelikovanr@mail.ru

\section{Для цитирования:}

Апреликова Н.Р. Становление представлений о познавательных потребностях в процессе развития психологической теории // Научные труды Московского гуманитарного университета. 2020. №5. C. 33-45. DOI: https://www.doi.org/10.17805/trudy.2020.5.4 